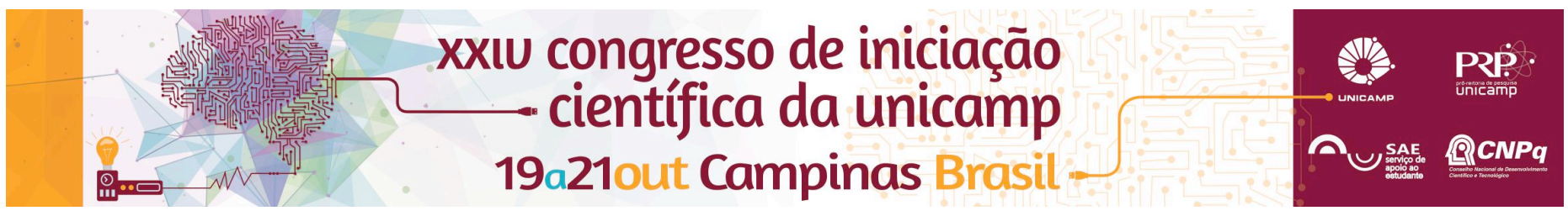

\title{
Montagem de microscópio óptico confocal para aplicações em nanoestruturas de semicondutores.
}

\section{Lucas M. Ruela*, Fernando likawa.}

\section{Resumo}

O objetivo do projeto é montar um microscópio óptico confocal de varredura para ser utilizado em estudo de propriedades ópticas de nanoestruturas semicondutoras. O microscópio confocal fornece imagens ópticas, cuja resolução é maior comparada com a de um microscópio convencional. Ele permite captar imagens tanto da luz refletida como também da luminescência da amostra. A varredura é feita através de dois espelhos móveis motorizados introduzidos em um microscópio óptico caseiro e controlados por um programa desenvolvido em LabView.

\section{Palavras-chave:}

microscópio, confocal, fotoluminescência.

\section{Introdução}

Atualmente, o Grupo de Propriedades Ópticas do IFGW utiliza um sistema de micro-fotoluminescência para estudos de nanoestruturas semicondutoras. Ele é basicamente formado por um microscópio convencional (caseiro) acoplado a um sistema de medidas de fotoluminescência. Nesse sistema, em cada posição da luz incidente sobre a amostra é realizada a medida espectral de emissão de luz da amostra. A substituição do sistema atual por um microscópio confocal de varredura seria uma melhoria para obter uma imagem óptica de melhor resolução, bem como a imagem de luminescência de um determina emissão óptica seletiva. Um microscópio óptico confocal é similar a um microscópio convencional. Ele também possui uma lente objetiva que quando iluminado por um feixe de laser focaliza-o sobre um único ponto, porém contém dois elementos adicionais no sistema: i) o elemento de varredura (espelhos móveis), que varia o ângulo de entrada luz incidente na objetiva e assim desloca o feixe em diferentes posições na superfície da amostra; ii) um orifício de abertura de dezenas ou centenas de micrometros que filtra o feixe refletido, donde o nome confocal se origina. O orifício de abertura seleciona unicamente a luz refletida, ou fotoluminescência, do ponto focalizado pela objetiva na amostra. O microscópio confocal é um conjunto de diversas partes, como lentes, espelhos, galvos (motores dos espelhos moveis), objetiva, detetores, câmera CCD, etc, cada um com particularidade própria. No projeto tivemos, portanto, oportunidade de aprender as propriedades desses componentes e suas limitações técnicas para realizar a montagem do microscópio e otimizar o sistema para obter a melhor resolução óptica.

\section{Resultados e Discussão}

Em um microscópio confocal é necessário detetar a luz refletida de uma pequena área. Para isso, foi utilizado como detetor um fotodiodo de Si (SD 112-43-11-221 da Advanced Photonix, Inc) cuja sensitividade para o comprimento do laser usado $(632.8 \mathrm{~nm}$ do laser de He$\mathrm{Ne}$ ) é por volta de $28 * 10^{6} \mathrm{~V} / \mathrm{W}$, o que é esperado ser razoável, pois a intensidade a ser detectada será baixa. O sistema de varredura é composto por dois galvomotores com espelhos fixados no eixo de cada um (GVS012 da Thorlabs) mais duas lentes idênticas para conduzir o feixe de diferente ângulo proveniente dos espelhos no centro da entrada da lente objetiva, portanto, essas lentes devem ser bem otimizadas. Foi montada uma fonte específica para os motores, pois eles precisam ser alimentados com uma tensão estável entre 15 a 18 VDC, tanto positiva quanto negativa. Como o feixe do laser passa por dois espelhos ocorre uma aberração quando chega na amostra e que isso deve ser corrigido por software. Foi desenvolvido programas em linguagem Labview da National Instruments para 0 controle individual dos motores e da leitura dos sinais medidos pelo fotodiodo. Utilizamos a placa DAQ da National Instruments para controlar o galvo-motor e a leitura do sinal do detetor. O sistema está sendo otimizado, tanto a parte da montagem óptica como do programa de controle, para que possamos adaptá-lo no sistema de medidas de fotoluminescência.

\section{Conclusões}

O microscópio óptico confocal foi montado satisfatoriamente faltando apenas ajustes finais para otimizar a resolução óptica e tornar o programa mais compacto de forma a ser acoplado ao sistema de medidas de fotoluminescência. $O$ projeto foi importante para aprender o princípio de funcionamento de um microscópio óptico confocal e dos componentes e dispositivos ópticos e eletrônicos constituintes do sistema. Além disso, tivemos oportunidade de aprender a programar em linguagem Labview para o controle do sistema.

\section{Agradecimentos}

Ao Conselho Nacional de Desenvolvimento Científico e Tecnológico - CNPq, através do Programa Institucional de Bolsas de Iniciação Científica - PIBIC, pela bolsa de Iniciação Científica. 